\title{
CTPPM (Context_Target_Problem_Pattern_Method): Procedure for framing and dealing with research problems
}

\author{
Minh-Hoang Nguyen \\ Centre for Interdisciplinary Social Research \\ Phenikaa University \\ Yen Nghia, Ha Dong, Hanoi 100803, Vietnam
}

September 21, 2021

$* * * * *$

By now, this year is the most progressive and productive year for me, with many meaningful studies since I started doing research [1-6]. I have wondered what made me progress so fast like that. Being able to frame a research problem and find out how to deal with it in a limited amount of time might be one of the reasons. In this essay, I would like to present the CTPPM procedure of framing and dealing with research problems. 'CTPPM' stands for five important notions that I always considered when starting a new research project: Context, Target, Problem, Pattern (Position), and Method.

I will take the research "Alice in Suicideland: Exploring the Suicidal Ideation Mechanism through the Sense of Connectedness and Help-Seeking Behaviors" as an example of applying the CTPPM [1]. Throughout the paper, I will call it "Alice."

Context: In any research, the first thing that I want to identify is the context I am going to research and its characteristics. Like in the "Alice" paper, a university was the location where my research took place. Furthermore, as the studied site (Asia Pacific University) has both international and domestic students from diverse countries, the context can be deemed a multicultural environment.

Target: Next, in a university, students are crucial constituents of the university context, so they were selected as my target. Besides students, faculties, staff, academic environments, school policies, and many other elements making up a university can also be considered potential targets.

Problem: After determining the target, I continued to identify their problems. Apparently, there are many problems that need to be studied among international university students, including academic performance, lifestyles, learning and intelligence, personalities, mental well-being, mental disorders, etc. In "Alice", I selected the problem of suicidal ideation.

Pattern (Position): Then, it is necessary to identify the patterns related to suicidal ideation among university students to come up with a research 
question/objective/hypothesis. Usually, the patterns are decided based on my observations and previously acquired knowledge. There also exists another faster way, which is referring to formerly constructed frameworks or theories. For example, I employed the Mindsponge mechanism to study the suicidal ideation mechanism $[7,8]$. Nevertheless, theories and frameworks are general, while the studied problem is narrow and focused, so the studied problem often requires only a small part of the theory or framework to be explained. Therefore, identifying the position of the studied problem within the theory or framework is needed.

Method: The final concern is thinking about the method that can be used to answer the research question, accomplish the research objective, or test the hypothesis. Because of the complexity of the suicidal ideation mechanism, Bayesian analysis was chosen to conduct the "Alice" study. More details of why Bayesian analysis was chosen can be found in the paper [1].

Here are only some of my brief thoughts, so they might not be sufficient for other peers and researchers to actually frame and deal with the research problem. Still, I hope the CTPPM procedure presented here can be a good reference for those trying to conduct research in a timely manner.

\section{References}

[1] Nguyen MH, Le TT, Nguyen HKT, Ho MT, Nguyen HTT, Vuong QH. (2021). Alice in Suicideland: Exploring the suicidal ideation mechanism through the sense of connectedness and help-seeking behaviors. International Journal of Environmental Research and Public Health, 18(7), 3681.

[2] Vuong QH, Nguyen MH, Le TT. (2021). Home scholarly culture, book selection reason, and academic performance: Pathways to book reading interest among secondary school students. European Journal of Investigation in Health, Psychology and Education, 11(2), 468-495.

[3] Vuong QH, Nguyen MH, Le TT. (2021). A Mindsponge-Based Investigation into the Psycho-Religious Mechanism Behind Suicide Attacks. Warsaw, Poland: De Gruyter / Sciendo.

[4] Vuong QH, Nguyen TTH, Pham TH, Ho MT, Nguyen MH. (2021). Assessing the ideological homogeneity in entrepreneurial finance research by highly cited publications. Humanities and Social Sciences Communications, 8, 110.

[5] Vuong QH, Nguyen TTH, Ho MT, Nguyen MH. (2021). Adopting open access in an emerging country: Is gender inequality a barrier in humanities and social sciences?. Learned Publishing, 8, 110. 
[6] Nguyen MH, Nguyen TTH, Le TT, Luong AP, Vuong QH. (2021). Gender issues in family business research: A bibliometric scoping review. Journal of Asian Business and Economic Studies, Early View.

[7] Vuong QH. (2016). Global mindset as the integration of emerging socio-cultural values through mindsponge processes: A transition economy perspective. In J. Kuada (Ed.), Global Mindsets: Exploration and Perspectives (pp. 123-140). New York: Routledge

[8] Vuong QH, Napier NK. (2015). Acculturation and global mindsponge: An emerging market perspective. International Journal of Intercultural Relations, 49, 354-367 